\title{
PIAGET, VYGOTSKY E WALLON: CONTRIBUIÇÕES PARA OS ESTUDOS DA LINGUAGEM
}

Caciana Linhares Pereira*

\begin{abstract}
RESUMO. O presente artigo aborda alguns aspectos da relação entre linguagem e pensamento na criança a partir das teorias de Piaget, Vygotsky e Wallon. Os aspectos analisados nos permitem situar estes autores no debate - tipicamente moderno - que envolve as complexas relações entre linguagem e pensamento. Constata-se que a modernidade do pensamento dos três autores comparece, sobretudo, no abandono de uma perspectiva instrumental da linguagem e no estabelecimento de proposições que tomam a linguagem como uma função constitutiva do próprio pensamento.
\end{abstract}

Palavras-chave: Linguagem; pensamento; criança.

\section{PIAGET, VYGOTSKY AND WALLON: CONTRIBUTIONS FOR LANGUAGE STUDIES}

\begin{abstract}
This article discusses some aspects of the relationship between language and thought in the child from the theories of Piaget, Vygotsky, and Wallon. The aspects analyzed allow us to place these authors in the debate - typically modern - which involves the complex relations between language and thought. It is noted that the modernity of the thought of the three authors attends, above all, in the abandonment of an instrumental view of language and the establishment of propositions that take the language as a constitutive function of one's own thinking.
\end{abstract}

Key words: Language; thought; children.

\section{PIAGET, VYGOTSKY Y WALLON: CONTRIBUCIONES A LOS ESTUDIOS DEL LENGUAJE}

\begin{abstract}
RESUMEN. El presente artículo presenta algunos aspectos de la relación entre lenguaje y pensamiento en el niño desde el punto de vista de Piaget, Vygotsky y Wallon. Los aspectos analizados nos permiten ubicar estos autores en el debate - típicamente moderno que involucra las complejas relaciones entre lenguaje y pensamiento. Se constata que la modernidad del pensamiento de los tres autores comparece, fundamentalmente, en el abandono de una perspectiva instrumental del lenguaje y en el establecimiento de proporciones que toman el lenguaje como una función constitutiva del propio pensamiento.
\end{abstract}

Palabras-clave: Lenguaje; pensamiento; niño.

O presente artigo aborda a dinâmica e o funcionamento da linguagem e as relações que a criança estabelece com o outro. Considerando que as teorias de Piaget, Vygotsky e Wallon, elaboradas no âmbito da psicologia e da educação, evidenciam e ao mesmo tempo impactam modos de pensar e teorizar sobre pensamento e linguagem na criança no século $\mathrm{XX}$, buscamos articular algumas proposições que alinham os respectivos autores às preocupações que marcaram esse século. Na história da psicologia e da educação, a compreensão do que é uma criança - de como uma criança constrói desenvolvimento e como a linguagem se articula a esse processo - modificou-se nestas ciências e nas práticas sociais. Se uma visão instrumental da linguagem colocava-a como uma coisa que estava fora do sujeito e que este acrescentava a si mesmo como mais uma aquisição, a qual funcionava como uma soma de elementos estanques que iam compor o construto maior do desenvolvimento do pensamento, alguns autores passam a atribuir novos contornos a esta perspectiva, mostrando como os processos cognoscitivos vão funcionar ao modo de uma equilibração majorante. Isso significa que o modo de funcionamento da linguagem articulada ao

Doutora em Educação Brasileira (Desenvolvimento, Linguagem e Educação da Criança) pela Universidade Federal do Ceará (UFC). Professora do Curso de Psicologia da Universidade de Fortaleza (UNIFOR). 
pensamento do sujeito se refaz a cada nova etapa, incorporando as aquisições anteriores em níveis de complexidade crescentes e reorganizando-as de maneira que a díade pensamento e linguagem se apresenta sutilmente estruturada. Nesse contexto, Piaget, Wallon e Vygotsky mostram que o conhecimento se dá a partir do sujeito em sua ação no mundo e conferem a esse processo sujeito-mundo uma dialeticidade ímpar nas teorizações sobre como conhecê-lo.

Depreende-se desse âmbito discursivo uma relação dialética entre homem e mundo que despolariza a velha querela entre a concepção de um sujeito que apenas atualizaria o conhecimento que traria consigo e a de que o meio determinaria tudo no desenvolvimento. Assim é que o pensamento engendra a sua linguagem - a linguagem possível correspondente a cada estágio do desenvolvimento - e o constitui como uma meia enodada consigo mesma. Na Modernidade começa-se não só a discutir o "para além" que a linguagem aponta, mas também a laborar sobre o próprio dizer. O signo é visto como cindido e se passa a problematizar o ato da enunciação, e não só o que é enunciado. Nesse ato do dizer - de natureza problemática, portanto - vê-se o deslizamento do desejo e pergunta-se da possibilidade de o sujeito assegurar-se do que é o real. O século XX foi atravessado por um dilema que se intensificou com a crítica da razão instrumental: o dilema entre a necessidade e a impossibilidade da representação. As discussões em torno da produção de sentido em tempos de barbárie, por exemplo, testemunham este dilema moderno que coloca em cena e interroga profundamente a categoria da representação - dilema que interroga fundamentalmente a relação entre a necessidade e a impossibilidade da representação da experiência. A ciência foi, assim, invadida por experiências sociais que recolocaram em cena a problemática relação entre a experiência e a narrativa que lhe corresponde, entre o objeto e o sujeito que o apreende. A linguagem é então questionada na sua posição de mediadora ou construtora de uma realidade propriamente humana. Nesse contexto encontramos nos três autores em questão - Piaget, Vygotsky e Wallon - o vigor de um pensamento que se realiza em direção a uma abordagem dialética das relações entre pensamento e linguagem.

\section{CONTRIBUIÇÕES DE WALLON}

Wallon, analisando as origens do conhecimento na criança, apresenta duas particularidades do pensamento infantil: a ausência do pensamento reflexivo, que configura a capacidade de pensar o próprio pensamento, e a ausência de tomada de posição, que configura a capacidade de assumir um ponto de vista. Tomaremos agora a segunda particularidade, que guarda relações com outro traço próprio do pensamento infantil: a alternância entre afirmações opostas. Wallon afirma que o pensamento infantil é "fluido" pelo menos sob dois aspectos: o da oscilação entre hipóteses contraditórias e o da interferência mútua entre linguagem verbal e imagem. A contradição é um princípio importante na teorização de Wallon sobre o pensamento e a linguagem na criança. Ele irá aparecer como motor de processos significativos na relação da criança com o conhecimento e é interessante que, na criança pequena, não se apresente ainda o princípio de contradição: “(...) o princípio de contradição é posterior às estruturas elementares que põem a consciência diante das representações" (Wallon, 1989, p. 95). As "experiências lacunares" das crianças (Wallon, 1984; 1989) se completam e se ampliam com as explicações dos adultos, o que não significa que haja acordo entre estas experiências e o que ela pode recolher da ambiência ideológica. Atravessada de modo intenso pelas contradições advindas dessa dupla origem de seu conhecimento (suas experiências e o conhecimento advindo do outro), a criança se esquiva e se protege do "sentimento agudo" provocado por tais contradições. Esta proteção também leva a criança a se deixar monopolizar totalmente por cada uma de suas ideias sucessivas, com exclusão das que as precediam, pois, "se não estivesse inclinada a se deixar monopolizar (...) sua confusão e, provavelmente, seu desânimo seriam grandes diante da inconciliável diversidade delas" (Wallon, 1989, p. 96). Por um lado, a criança não toma posição, no sentido de que não assume de forma estável e coordenada um ponto de vista seu; por outro, ela se deixa monopolizar por ideias de uma forma que poderíamos chamar "absolutizante". Esta monopolização, então, refere-se muito mais à fluidez da criança em relação aos diversos pontos de vista com que se defronta - uma espécie de proteção diante de uma dispersão ameaçadora - do que à possibilidade de assumir uma "posição" no discurso que leve em conta o "eu" possibilidade que Wallon denomina "tomada de posição" em relação a um ponto de vista seu.

É importante destacar que há contradição entre as experiências pessoais e entre estas experiências e o conhecimento advindo do outro. Este é um dado importante, pois não se trata de um conflito de ordem interna $\mathrm{x}$ externa, mas de um conflito que coloca em cena os elementos polimorfos e díspares da 
subjetividade da criança (Wallon, 1989; 1995). A criança opera com imagens e palavras, mas se as imagens (de um ponto de vista perceptivo) podem advir de sua experiência pessoal, as palavras advêm, necessariamente, do outro (da cultura). A percepção, destituída do seu elemento simbólico organizador, se estabelece sem mediação. A imagem, no entanto, não se reduz à percepção: já é um construto simbólico atravessado pela linguagem - portanto, pelo outro. Considerando estas relações, podemos situar a afirmação de Wallon segundo a qual "a linguagem tem precedência sobre a realidade": "É, inicialmente, a linguagem, o material ou saber verbal de Gelb e Goldstein, que contém significações mais ou menos obscuras, sobre as quais ela (a criança) precisa exercer sua sagacidade, formular hipóteses, variando-as e retificando-as segundo as circunstâncias" (Wallon, 1989, p. 96). Para Wallon, uma das características do funcionamento linguístico da criança (que não se separa do cognoscente) é a interferência mútua da linguagem e das imagens perceptivas. Não obstante, a linguagem apresenta condições próprias de existência e de desenvolvimento, que podem subsistir e funcionar mesmo quando a ideia não é capaz de evocar a palavra e nem a palavra, a ideia. A aprendizagem da linguagem promove um tipo de funcionamento em que a linguagem se antecipa ao conhecimento e à compreensão. Para o autor, a linguagem não se reduz a uma simples coleção de etiquetas das quais a criança extrairia noções que ela já consegue conceber realmente, pois "através do vocabulário e da sintaxe, ela tem, em potencial, um mundo de relações, de afinidades ou de oposições, que precedem o momento no qual ela receberá de sua aplicação a situações ou a objetos determinados, significações precisas" (Wallon, 1989, p. 102).

A interferência mútua entre a linguagem e as imagens perceptivas acontece ao modo do conflito, configurando-se como conflito entre o sentido literal e os esquemas experimentais dos quais a criança pode dispor. Este sentido literal a criança recolhe das expressões de linguagem que ouve. Ela extrai significações destas expressões e só então as coloca em relação com as experiências de ordem experimental. Vejamos dois exemplos citados por Wallon nos quais podemos visualizar o que ele nomeia "interferência entre palavra e imagem" e, ao mesmo, tempo, o que indica como a precedência da linguagem na produção da significação. Wallon (1989) apresenta a fala de uma criança de oito anos:

\begin{abstract}
“- A água se mexe. - É a corrente que faz ela mexer. - É um fio. - Um fio grande (como um fio elétrico que ela mostra). (...) - Ele viu no lugar onde a gente vê. No fundo da água. $\mathrm{Na}$ fábrica. - Outros homens viram. - É um fio de barbante." (p. 101). A criança prossegue: "- Os bondes mexem com a corrente. - É feita com um fio de ferro e barbante. - É como a corrente da casa dele para acender a luz. - A corrente da água é a mesma coisa. - O Sena é a corrente" (Wallon,1989, p. 101).
\end{abstract}

Wallon observa que a criança recebe de seu meio uma palavra e lhe atribui uma significação calcada na imagem de objetos ou de atividades que lhe são familiares; ela interpreta o que lhe faz enigma segundo o que já pertence à sua experiência, no entanto essas imagens podem não convir. Então a criança pode estabelecer acordos que produzem efeitos barrocos ou reconhecer sua incompreensão. Neste segundo exemplo, vemos a criança interpretar, agrupar, modificar suas impressões perceptivas. Como observa Wallon (1989), o efeito destas operações lembra o trocadilho, o que exemplifica no diálogo com outra criança de oito anos: "- De onde vêm os pintinhos? Vêm dos ovos. - Os ovos estão vivos? - Não. - Por que eles não estão vivos? - Porque eles não têm olhos. Os cegos têm olhos? - Têm, mas eles estão fechados. Se eles não tivessem olhos, eles não estariam vivos?" (p. 100). A criança então responde: “- Estariam. (sorriso). - O que mais é preciso para estar vivo? Basta ter olhos? - É. - Quando a gente morre a gente ainda tem olhos? - Por que o corpo se abriu. - Como é isso? - Esqueceram de fechá-lo... - Como? O corpo pode abrir e fechar?" (p. 100). Observemos agora a resposta: “- Com botões. - Você tem botões? - Não (longo estremecimento como que de medo)" (p. 100). A evocação provocada pela palavra é mais forte, prevalecendo sobre a experiência. Wallon diz que, na criança, a coesão entre as palavras e as significações ainda é frouxa, o que nos lembra o postulado freudiano da sobredeterminação presente nos sonhos e nos sintomas.

Assim, o que Wallon denomina "coesão frouxa" se aproxima do que Freud estabelece como a sobredeterminação própria dos mecanismos de linguagem inconscientes. Na sobredeterminação, uma imagem sustenta (agrega) várias palavras ou elementos linguísticos. A imagem, aqui, é uma espécie de constelação de signos, agrupados de modo "frouxo". Uma palavra também pode estabelecer conexões com várias outras palavras e 
evocar múltiplas significações, sem que uma se sobreponha às outras. Diante da pergunta "O que as pedras fazem quando a gente as joga na água?” a criança pode estabelecer conexões entre cair na água e nadar, e assim responder: "Elas caem na água e depois elas nadam". A criança tem condições de formular e expressar um conhecimento mais preciso sobre a pedra na água tanto que, depois, diz: "não, elas caem no fundo da água"- mas é levada pelas associações frouxas que se criam entre cair na água e nadar. Estes procedimentos associativos acontecem, no adulto, no espaço do sonho e da criação artística, passando por uma espécie de controle ou regulação na vida de vigília. Na criança, são procedimentos que aparecem de modo explícito, constituindo formas específicas do seu funcionamento linguístico e mental.

Wallon, diferentemente de Piaget, enfatiza o desenvolvimento infantil como um processo descontínuo e eminentemente social. Vimos como esta descontinuidade aparece, em suas formulações sobre a linguagem e o pensamento, sob a forma da contradição entre afirmações verbais. Diante destas contradições a criança irá se movimentar, buscando correspondências entre palavras e imagens, de modo a poder formular explicações plausíveis para os enigmas que tenta decifrar. Quando falamos de explicações plausíveis, falamos de explicações menos marcadas por afirmativas contraditórias. Em relação ao lugar do outro e da cultura, vimos que a linguagem tem "precedência" em relação à produção de conhecimento, o que significa dizer que o universo simbólico estrutura e organiza a relação da criança com a realidade. Este universo simbólico, para Wallon, encontra-se referido às palavras que a cultura oferta à criança: às expressões de linguagem, às explicações que ouve sobre suas origens e acontecimentos da vida, etc. A posição da criança diante desse outro da cultura é fundamental para compreendermos, por exemplo, o que Wallon nomeia de "ausência de tomada de posição" da criança. Esta oscilação entre afirmações não corresponde apenas ao "pequeno repertório" de conhecimentos experimentais da criança (que Wallon confirma), mas também à sua posição diante do outro: a criança recebe do outro a linguagem, e a recebe num momento em que não demarcou as fronteiras entre o eu e o outro. Assim, o que recebe toma esta forma "polimorfa" e "díspar" daquilo que não é exatamente "seu" nem de "outro".

Wallon observa algo muito interessante na relação que a criança estabelece com as "origens" do seu conhecimento: ela - a criança - afirma que o conhecimento (que ela produziu) é seu e de outro (outro que aparece, regularmente, na figura do pai) ${ }^{1}$. A criança se mantém em contato com esta dimensão estrangeira do saber: sabe que seu conhecimento advém de si e de outro... Concluiremos nosso recorte sobre algumas contribuições de Wallon lembrando que, para este autor, a linguagem, antes de expressar uma representação, instaura um tipo de atividade projetiva caracterizada por realizações ideomotoras (onde as imagens são projetadas em atos mentais). Se a representação está ligada ao gesto que a desencadeia, os ideomovimentos são os precursores da representação. Sabemos que as condutas imitativas assumem um lugar fundamental na obra de Wallon, que demonstra como estas condutas envolvem a percepção de uma situação, a estruturação dos seus elementos sensoriais e a reconstituição do conjunto. A imitação e o simulacro (representação de um objeto na ausência deste ou de seus movimentos) antecedem a inteligência discursiva e Wallon irá afirmar que, enquanto a imitação materializa uma sucessão de atos, a representação é atemporal, autônoma e definitiva. $\mathrm{Na}$ imitação a predominância é do plano motor e na representação a predominância é do plano simbólico, embora os dois planos estejam sempre em relação e se apoiem mutuamente.

\section{CONTRIBUIÇÕES DE VYGOTSKY}

Quando Vygotsky aborda a relação entre o pensamento e a fala nos estágios iniciais do desenvolvimento filogenético e ontogenético, afirma não encontrar nenhuma interdependência específica entre as raízes genéticas do pensamento e da palavra (Vygotsky, 2001). Desse modo, a relação entre pensamento e palavra não é um pressuposto para o desenvolvimento histórico da consciência. Existem, no desenvolvimento da criança, um período prélinguístico do pensamento e um período préintelectual da fala; no entanto, embora afirme a inexistência de um elo primário entre pensamento e fala, Vygotsky não se alinha às teorias associacionistas que tomam o pensamento verbal como resultante da

\footnotetext{
“A contradição é ainda mais explícita quando a mesma criança invoca o testemunho de seu pai, após ter dito que ela sabia a coisa por si própria. Inúmeras crianças atribuem, de boa fé, suas idéias, às vezes mais infantis e extravagantes, a uma tradição, que elas declaram, quase sem exceção, vir de seus pais (...). Parece que o pai é, para a criança, um protótipo de autoridade, ao mesmo tempo que a testemunha da ambiência extra-familiar e, mais tarde, o vínculo com o que precedeu a criança no mundo das origens" (Wallon, 1989. p. 95).
} 
união externa entre pensamento e fala. Aliás, o fracasso destas teorias, segundo este autor, foi tributário justamente deste tipo de conexão mecanicista, que tentava explicar as propriedades do pensamento verbal fragmentando-as em seus elementos componentes. Vygotsky propõe, então, a substituição da análise por elementos pela análise por unidades que ele encontra nos significados das palavras. O significado de uma palavra constitui uma unidade indecomponível dos dois processos, de forma que não podemos dizer que ele seja um fenômeno da linguagem ou um fenômeno do pensamento. $\mathrm{O}$ autor observa que uma palavra desprovida de significado não é palavra, e sim, um som vazio. O significado é um traço constitutivo da palavra, é a própria palavra no seu aspecto interior. Do ponto de vista psicológico, a palavra corresponde a uma generalização ou conceito: "Toda generalização, toda formação de conceitos é o ato mais específico, mais autêntico e indiscutível do pensamento. Consequentemente, estamos autorizados a considerar o significado da palavra como um fenômeno do pensamento" (Vygotsky, 2001, p. 398).

O significado da palavra, no entanto, só é um fenômeno de pensamento na medida em que o pensamento se materialize na palavra. Esta materialização pressupõe um processo de construção que não se resume a um processo de simples associação. Assim, o novo e essencial na teoria de Vygotsky é a investigação sobre o desenvolvimento dos significados das palavras. Para este autor, as investigações em torno do desenvolvimento do significado das palavras se reduziram a investigações sobre as mudanças nas conexões associativas entre palavras e objetos isolados. Não obstante, não é só o conteúdo que se altera nesta mudança, mas também o modo pelo qual a realidade é generalizada e materializada em uma palavra. Aqui, chegamos a uma problematização crucial realizada por Vygotsky: se o associacionismo não investiga as transformações dos modos de generalização e materialização do significado, também não pode explicar as transformações estruturais e psicológicas que ocorrem no desenvolvimento da linguagem das crianças. As escolas e tendências psicológicas (como a Escola de Wuerzburg e da Gestalt, e autores como Selz e Ach) não deram o devido valor ao fato de que todo pensamento é uma generalização, estudando a palavra e o significado sem fazer referência a seu aspecto evolutivo. Esta lacuna nas investigações abriu para Vygotsky uma questão que poderíamos assim formular: como os significados das palavras se alteram em sua natureza intrínseca - e, deste modo, se altera a relação entre pensamento e palavra - o que podemos apreender sobre a relação entre pensamento e palavra a partir de nossas investigações com crianças? Esta pergunta, que norteará a pesquisa de Vygotsky, nos interessa de modo particular.

$\mathrm{O}$ desenvolvimento linguístico da criança revela a presença de um trajeto distinto das esferas fonética (que em algumas traduções encontramos sob a expressão "esfera física e sonora da linguagem") e semântica. Quando a criança apresenta uma fala exterior, ela começa por uma palavra e avança no sentido de articular duas ou três palavras entre si. Mais tarde ela elabora frases complexas, chegando à fala corrente, que é composta por um todo articulado de frases complexas. Neste sentido, no que diz respeito ao aspecto físico e sonoro da linguagem, a criança caminha da parte para o todo. Quanto ao aspecto semântico, o vetor assume o sentido inverso: a criança parte do todo para as unidades menores. A primeira palavra pronunciada pela criança não tem o significado isolado da palavra, mas o significado de uma frase inteira ${ }^{2}$. Com o tempo, a criança passa a dividir o pensamento em unidades isoladas. $\mathrm{O}$ avanço da fala em direção ao todo diferenciado de uma frase ajuda o pensamento da criança a progredir de um todo homogêneo para partes bem definidas. Assim, a linguagem não comparece, em Vygotsky, em sua dimensão puramente instrumental, mas assume um lugar central na própria estruturação e organização do pensamento: "A linguagem não serve como expressão de um pensamento pronto. Ao transformar-se em linguagem, o pensamento se reestrutura e se modifica. O pensamento não se expressa, mas se realiza na palavra" (Vygotsky, 2001, p. 412).

O próximo aspecto a ser investigado por Vygotsky é o da precedência da gramática sobre a lógica. Esta precedência - que aparece em Wallon sob a forma da precedência da linguagem em relação ao conhecimento advindo da experimentação - também é destacada por Piaget, que demonstra que a criança utiliza orações subordinadas muito antes de apreender os significados correspondentes a essas formas sintáticas. Vygotsky sublinha que esta espécie de divergência - que propomos

Esta ocorrência é bastante estudada na área de aquisição da linguagem, constituindo o que se nomeia de modo corrente a "holófrase". Lemos realizou uma pesquisa de doutorado muito interessante e reveladora sobre as relações entre a constituição subjetiva da criança e a holófrase. Indicamos um artigo que apresenta alguns achados da pesquisa: Lemos (2002). Sobre fragmentos e holófrases. Colóquio LEPSI: Os adultos, seus saberes e a infância. São Paulo: IP/FEUSP. 
entender também como heterogeneidade - entre os aspectos semântico e fonético da linguagem é ainda mais surpreendente nos adultos. $\mathrm{O}$ autor retira um exemplo de Vossler, observando que no prólogo de sua peça "O duque Ernst von Schwaben", Uhland diz: "Uma cena grave irá se descortinar diante de vós" (Vygotsky, 2001, p. 413). Na estrutura gramatical da frase, "uma cena grave" é o sujeito, e "irá descortinar-se" é o predicado, mas do ponto de vista da estrutura psicológica daquilo que quis dizer o poeta, "irá descortinar-se" é o sujeito e "uma cena grave" o predicado. O poeta quis dizer, segundo a análise do autor, que o que vai acontecer diante de vós é uma tragédia e a primeira coisa que o espectador teve em mente foi que diante dele se passaria uma cena: "É isto que diz a frase, isto é, este é o sujeito psicológico. A novidade acrescentada a este sujeito é a noção de tragédia, que é o verdadeiro predicado psicológico" (Vygotsky, 2001, pp. 413-414).

Vygotsky retoma, ainda, elaborações presentes no livro Psicologia da arte $^{3}$ para exemplificar o que entende, na esfera da linguagem, como a flutuação constante entre os ideais da matemática e a harmonia imaginativa ${ }^{4}$ (Vygotsky, 2001, p. 413). Traduzindo a fábula A cigarra e a formiga, Krylov substituiu a cigarra de La Fontaine por uma libélula. Vygotsky atenta para o fato de que, em francês, cigarra é uma palavra feminina e adequada para simbolizar uma atitude despreocupada e alegre. Dessa forma, a nuança se perderia numa tradução literal, já que em russo cigarra é masculino: "Ao optar por libélula, que em russo é feminino, Krylov descartou o significado literal em favor da forma gramatical necessária para transmitir o pensamento de La Fontaine (Vygotsky, 1989, p. 110). A criança, a princípio, utiliza formas verbais e significados sem ter consciência de ambos como coisas separadas. A consciência linguística primitiva toma a palavra como parte integrante do objeto que denota. Experiências mostraram que a criança explica o nome dos objetos pelos seus atributos. Um animal chama-se vaca

3 Vygotsky, Lev Semenovitch (1999). Psicologia da arte. Trad. Paulo Bezerra. São Paulo: Martins Fontes. Consultar, especificamente, na parte III - Análise da reação estética -, o capítulo Análise da fábula (103-140).

4 "O acordo entre o sujeito gramatical e o sujeito psicológico não é tão predominante como tendemos a presumir -- antes pelo contrário, é um requisito raramente satisfeito. Não são só o sujeito e o predicado que têm os seus duplos psicológicos, pois também o gênero, o número, o caso, o tempo, o modo, o grau gramaticais o possuem. Uma exclamação espontânea, que do ponto de vista gramatical é errada, pode ter encanto e valor estético. A correção absoluta só se consegue para lá da linguagem natural, na matemática. A nossa linguagem quotidiana oscila constantemente entre os ideais da harmonia matemática e os da harmonia imaginativa" (Vygotsky, 2001, p. 413). porque tem chifres, outro se chama bezerro porque seus chifres ainda são pequenos, e outro se chama cão porque é pequeno e não tem chifres (Vygotsky, 2001, p. 418). Neste ponto, podemos anunciar o seguinte postulado de Vygotsky: "a capacidade que tem uma criança de comunicar-se por meio da linguagem relaciona-se diretamente com a diferenciação dos significados das palavras na sua fala e na sua consciência" (Vygotsky, 1989, p. 111-112). Para fundamentar tal postulado, o autor recorre à característica básica da estrutura dos significados das palavras: na estrutura semântica há uma distinção entre referente e significado; de modo correspondente, há a distinção entre o nominativo de uma palavra e sua função significativa. Investigando a dimensão evolutiva da linguagem, Vygotsky se depara com a seguinte regularidade genética: na criança pequena, só comparece a função nominativa e, do ponto de vista semântico, a referência objetiva. A significação independente da nomeação e o significado independente da referência só se apresentam posteriormente, ou seja, são frutos de uma construção extremamente complexa.

$\mathrm{O}$ que este trajeto nos revela da natureza psicológica da linguagem? Se a linguagem possui uma relação estreita com a função de endereçamento ao outro, se constitui uma possibilidade fundamental de participação da criança nas trocas simbólicas, como as reflexões de Vygotsky sobre a evolução da linguagem contribuem para a compreensão dos modos como a criança se situa nestas trocas simbólicas? Responder a esta pergunta exige certo recuo, que foi o mesmo realizado por Vygotsky: recuo em direção às manifestações simbólicas anteriores ao surgimento de uma fala endereçada (que chamaríamos, com Piaget, de fala comunicativa). Depois de retomar as distintas significações que foram atribuídas ao conceito de "linguagem interior" ou "endofasia", Vygotsky situa o conceito com o qual irá operar: a linguagem interior é a fala para si mesmo; a linguagem exterior é para os outros (Vygotsky, 1989, p. 425) ${ }^{5}$. Para Vygotsky, a

\footnotetext{
É importante lembrar que os termos fala, linguagem e discurso aparecem em momentos diferentes das obras de Vygotsky, constituindo motivo de importantes discussões envolvendo tradutores e estudiosos do autor. No âmbito deste trabalho, não aprofundaremos esta discussão, mas ressaltaremos, para efeito de esclarecimento quanto ao uso das traduções, que estamos trabalhando com duas traduções do livro A construção do pensamento e da linguagem - uma de 1989 e outra de 2001 - e estamos optando ora por uma tradução, ora por outra; nesta escolha seguimos o seguinte critério: optamos pela tradução que utiliza o termo fala quando Vygotsky está enfatizando o aspecto físico e sonoro da linguagem e o termo linguagem quando o autor está se referindo à linguagem em sua dimensão mais ampla, que poderíamos muitas vezes tomar como equivalente da dimensão discursiva. Como não existe um padrão nas duas
} 
linguagem interior é precedida pela linguagem egocêntrica: a linguagem egocêntrica desaparece quando a linguagem interior começa a se desenvolver, uma se transformando na outra. A linguagem egocêntrica é um fenômeno que corresponde à transição das funções interpsíquicas para as intrapsíquicas, evidenciando o curso geral das funções psicológicas superiores, que parte da atividade social e coletiva para a atividade mais individualizada. Esta linguagem não se restringe a "acompanhar" a atividade da criança, mas "orienta" a própria atividade mental (Vygotsky, 1989, p. 115).

Vygotsky problematiza as formulações piagetianas sobre a linguagem egocêntrica sob pelo menos dois aspectos: o primeiro refere-se ao fato de que esta linguagem não corresponde a um pensamento "individual", mas, pelo contrário, corresponde a uma atividade do pensamento atravessada pelo "coletivo"; o segundo refere-se ao fato de que esta linguagem não desaparece, mas dá lugar à linguagem interior. Em nosso entendimento, a diferença que Vygotsky considera tão marcante entre suas formulações e as de Piaget pode ser relativizada pelas proposições de Piaget relativas à constituição do eu. Para Piaget, o egocentrismo é paradoxal, pois se trata de um egocentrismo sem eu. Esta categoria de egocentrismo em Piaget se encontra muito articulada ao que ele chama de categorias de artificialismo e animismo. Se tomarmos apenas os textos de Piaget relativos a estas categorias, veremos que elas se referem a propriedades do pensamento infantil que fazem a criança projetar justamente pela ausência de consciência do eu características suas nos objetos (por exemplo, nos objetos da natureza) ou materialize funções do pensamento a partir das propriedades do mundo físico (as pesquisas de Piaget mostram como a criança materializa o pensamento na voz, conferindo ao pensamento a propriedade de atuar sobre as pessoas e coisas como os objetos do mundo físico).

Neste sentido, o egocentrismo se refere menos a um indivíduo centrado em si mesmo do que a um modo de assimilação do real marcado por uma indiferenciação de planos (interno/externo e subjetivo/objetivo). Estas questões se tornam mais claras, a nosso ver, sobretudo com a leitura dos livros A representação do mundo na criança (s/d) e $A$ formação do símbolo na criança (1975), onde o autor expõe suas pesquisas envolvendo as noções de representação e simbolismo a partir da experiência da

traduções (ora a tradução de 1989 é mais rigorosa, ora a tradução de 2001), cotejamos as duas e escolhemos a que mais se adequa ao critério que estabelecemos. criança. Como não podemos, aqui, aprofundar esta discussão - que mereceria um espaço maior de apresentação - gostaríamos pelo menos de anunciar uma hipótese: o que Vygotsky considera de ordem coletiva e social na linguagem egocêntrica não é completamente avesso ao que Piaget considera uma manifestação do pensamento egocêntrico, pois as noções de coletivo e social em Vygotsky (no que diz respeito à linguagem da criança) estão articuladas ao fato a linguagem e o próprio pensamento se constituírem no endereçamento ao outro. Poderíamos depreender da afirmação de que "a fala para si mesmo origina-se da fala para os outros" (Vygotsky, 1989, p. 114) que a fala, desde seu surgimento, encontra-se referida ao outro.

Uma proposição de Vygotsky nos ajuda a avançar na compreensão desse outro com quem a criança se relaciona: a criança fala ao outro falando consigo mesma; ou seja, o que Vygotsky descobre é que a criança, para pensar, dirige-se ao outro por meio da fala. Não só a fala comparece como estruturante do pensamento, mas o outro também, pois é em função deste outro que o pensamento se constrói. Pode-se, porém, perguntar: quem é este outro para quem a criança se dirige? Se Vygotsky afirma que a fala orienta o pensamento, é a própria criança que é orientada pela fala: a criança é esse outro a quem endereça sua própria fala. Aqui entramos num território estranhamente familiar ao território piagetiano: esse outro não é a criança do ponto de vista de um eu, mas justamente um outro que se situa entre o outro e o eu. A linguagem egocêntrica, como bem aponta Vygotsky, é um fenômeno de transição transição que testemunha a existência de um sujeito profundamente atravessado pelo outro, um sujeito que fala para o outro como fala para si e recebe do outro a matéria-prima do seu pensamento (as palavras). A criança nos defronta com uma zona difusa, em que os conceitos de individual e coletivo, interno e externo, assumem formas complexas. Esta complexidade é o que torna o debate entre Piaget e Vygotsky extremamente árido, pois o egocentrismo de Piaget pode se revelar estranhamente coletivo e o coletivo de Vygotsky se revelar tipicamente egocêntrico.

Retomemos agora algumas contribuições da pesquisa de Vygotsky sobre a linguagem egocêntrica. Esta linguagem corresponde a um momento da vida da criança em que ela tem a ilusão de estar sendo compreendida pelo outro. Esta interpretação de Vygotsky se relaciona com sua compreensão de que a linguagem egocêntrica deriva da falta de diferenciação entre a fala endereçada para si mesmo e a fala endereçada ao outro. Seu desaparecimento acontece 
quando a criança vai perdendo esta ilusão de que o outro a compreende (justamente por estar "indiferenciado" dela mesma). Neste ponto a teoria de Vygotsky contribui para a compreensão da importância das relações de grupo, pois estas relações promovem uma necessidade de "ajuste" da criança ao outro. A criança passa a se fazer compreender ao se dar conta de que o outro não compartilha de seus pensamentos e estados afetivos. Estas reflexões de Vygotsky podem ser complementadas pela importância que Piaget também atribui ao grupo e ao outro, sobretudo em sua obra $A$ construção do juízo moral, para o desenvolvimento da capacidade de se descentrar e de considerar as diversas perspectivas presentes em uma dada situação. Piaget lembra, por exemplo, as tomadas de decisões coletivas e o fato de que a autonomia não se refere ao "pensar por si", mas a ser capaz de tomar posição a partir da coordenação de pontos de vista diferentes do próprio.

Vygotsky postula três peculiaridades semânticas da linguagem interior: o predomínio do sentido sobre o significado; a presença de algo semelhante à aglutinação (diversas palavras fundem-se numa única; a nova palavra não exprime aqui uma ideia complexa, mas sentidos superpostos); o influxo de sentido (os sentidos das palavras se combinam e se unificam; os sentidos de diferentes palavras fluem um dentro do outro, influenciam-se, de modo que os primeiros estão contidos nos últimos). Embora postule que a linguagem egocêntrica tomará o destino da linguagem interior e que a criança também avançará na elaboração cada vez maior da linguagem exterior (social), Vygotsky observa alguns pontos em comum entre as duas linguagens (interior e exterior). Percebe que esta última apresenta traços da primeira: a predicação, o declínio da vocalização, a predominância do sentido sobre o significado, a aglutinação, etc.; no entanto, estes traços aparecem na fala exterior sob algumas condições. A arte é um campo, por exemplo, em que se observa esta linguagem social - endereçada - mas atravessada pelos modos de funcionamento da linguagem interior.

\section{CONTRIBUIÇÕES DE PIAGET}

Abordando algumas contribuições de Piaget para os estudos da linguagem na criança, poderíamos iniciar afirmando que, para este autor, o pensamento representativo (rudimentar) tem início com a capacidade de evocar objetos e eventos ausentes. Esta nova aquisição (representativa) promove transformações que ampliam os conhecimentos advindos da inteligência prática e permite a elaboração de operações mentais complexas que os atos, por sua limitação temporal, não alcançam. O desenvolvimento da inteligência prática leva o sujeito a coordenar estados de uma ação, interligados por curtas antecipações e reconstituições momentâneas em torno de um objeto concreto. A inteligência conceitual, por sua vez, possibilita a constituição de representações de conjunto (fusão) e o acesso à atividade classificatória e reflexiva. Como Wallon, Piaget também atribui uma importância capital à atividade imitativa, que já se observa desde os primeiros meses de vida. Partindo da ideia de um indivíduo indiferenciado, os estudos de Piaget sobre a atividade imitativa acompanham este descentramento sucessivo da criança. Se a imitação comparece, de início, como uma cópia direta dos gestos do adulto, por outro lado, vai assumindo a forma dos atos da inteligência representativa. A atividade representativa se sustenta, sobretudo nos primeiros anos de vida, na imitação diferida e interiorizada, que comparece no jogo simbólico e na própria atividade linguística da criança.

Embora em algumas obras Piaget não tome a linguagem como constitutiva da inteligência e do pensamento, chegando mesmo a afirmar a independência do desenvolvimento da inteligência em relação à linguagem, consideramos importante estabelecer um diálogo entre estas afirmações e seus estudos relativos à formação do símbolo na criança. Sabemos que Piaget toma a linguagem como uma condição necessária na construção das operações lógicas, mas não necessariamente atribui a ela uma importância capital. Em relação a estas construções lógicas, são importantes os processos de abstração empírica que os indivíduos realizam sobre os objetos (e toda a atividade de coordenação que esta implica). Não obstante, gostaríamos de retomar afirmações do autor que vinculam a linguagem aos modos mais primitivos de organização do real pela criança. Abordando as categorias representativas, encontramos a afirmação de que, com a conquista da linguagem, estas categorias se desenvolvem no campo das manipulações práticas, mas, "por outro lado, as diversas conexões causais e espaçotemporais ultrapassam esse domínio da ação (...) e ocasionam, em particular, sob a influência dos "porquês" e das questões de origem que a linguagem permite multiplicar, uma proliferação de representações espaciais e temporais, de mitos pseudo-explicativos... (Piaget, 1975, p. 313). Piaget (1975) apresenta exemplos que nos levam diretamente a Wallon e suas considerações sobre as "coesões frouxas" que 
comparecem na linguagem e no pensamento da criança pequena: "Ao 1;8 (11), J. vendo pela janela um nevoeiro que se forma na montanha (a cerca de 200m) exclama: "Nevoeiro, fumaça, papai", em alusão à fumaça de seu cachimbo" (p. 314). No dia seguinte, a criança diz simplesmente "Nevoeiro papai"; e no banho, mostra o vapor, dizendo: "Nevoeiro, fumaça". Um mês mais tarde ela diz sem cessar: "Nuvens, papai" ou "Nevoeiro, papai" ao rever brumas.

Piaget, analisando estas falas, diz que esse domínio é de uma ordem inteiramente outra do que o das intuições lógicas, numéricas ou espaciais, que decorrem da manipulação e da verificação perceptiva. A causalidade aqui é verbal, e não intuitiva: "Em particular, é interessante para nossa finalidade atual, constatar que todos os intermediários relacionam, nesse terreno, o jogo propriamente dito e a crença séria". (Piaget, 1975, p. 318). Em todo esse texto Piaget busca estabelecer uma equivalência estrutural entre o simbolismo presente na criança, o simbolismo onírico e o pensamento simbólico de uma forma geral. Desta forma, embora formule um quadro evolutivo das formas de representação, esta evolução não quer dizer que o aparecimento de novas formas anule uma base sobre a qual se organiza a atividade simbólica. Se a assimilação egocêntrica (que especifica as estruturas pré-conceptuais) se encontrar em continuidade com a assimilação simbólica característica dos símbolos lúdicos, e mesmo oníricos, "essa atribuição de caracteres subjetivos a objetos materiais e externos não apresenta mais problema especial e surge como um simples caso particular do mecanismo muito geral que constitui o pensamento simbólico" (Piaget, 1975, p. 322). Teorizando sobre o pensamento simbólico, o autor trabalha o tempo inteiro com o material linguístico que recolhe em suas pesquisas. Estabelece relações recíprocas entre linguagem e pensamento, apontando as relações entre as manifestações das crianças (suas falas) e suas interferências no plano da construção do símbolo: "o símbolo é a precisamente a expressão da necessidade em que se encontra o espírito de projetar seu conteúdo sobre os objetos, à falta de consciência de si, enquanto que o progresso operatório está necessariamente ligado a um desenvolvimento reflexivo que leva a esta consciência e dissocia assim o subjetivo da realidade exterior" (Piaget, 1975, p. 327).

O que gostaríamos de destacar é que esta "falta de consciência de si” presente no pensamento operatório indica modos de funcionamento mental presentes na vida do indivíduo, e não "fases" evolutivas em que o pensamento simbólico corresponderia à criança e o pensamento operatório ao adulto. O que Piaget investiga, precisamente, é a gênese destes modos de funcionamento, portanto, investiga os modos de comparecimento do pensamento operativo e simbólico na criança. Em suas investigações sobre o pensamento simbólico, Piaget oferece um rico material sobre o modo como a linguagem se relaciona com as preocupações vitais na vida da criança (Piaget cita a preocupação com a questão das origens da vida e todos os seus desdobramentos relativos à origem dos seres vivos, dos fenômenos naturais, dela mesma, etc.). Como vimos no exemplo do nevoeiro, a palavra permite a ultrapassagem do que seria um mero encontro perceptivo com o objeto, em direção à construção de constelações simbólicas características do funcionamento mental da criança. A linguagem, sem dúvida, participa ativamente da construção destas constelações.

\section{CONSIDERAÇÕES FINAIS}

Concluiremos destacando a importância dos três autores para o abandono de uma perspectiva instrumental da linguagem e o estabelecimento de proposições que tomam a linguagem como uma função constitutiva do próprio pensamento. Os autores questionam uma concepção da linguagem que considera seu funcionamento a partir da soma ou associação de elementos estanques. Questionam, dessa forma, a tese de um pensamento que se associaria às construções da linguagem numa vinculação de ordem mecânica. Para estes autores, pensamento e linguagem se modificam e se reestruturam em relações complexas, não havendo realidade anterior à linguagem ou fora dela.

Segundo Wallon, a criança opera com imagens e palavras que advêm de sua experiência pessoal e do outro. Neste autor observamos uma problematização da diferença entre percepção e imagem que faz a imagem ultrapassar a percepção, na medida em que exige um elemento simbólico organizador. A imagem não se reduz à percepção, sendo já um construto atravessado pela linguagem. $\mathrm{O}$ estatuto da linguagem como fundamento da organização da realidade - que consideramos como uma problemática específica e essencial na modernidade - é encontrado na consideração de que a linguagem precede a realidade. É sobre a linguagem que a criança precisa exercer sua sagacidade, e o funcionamento linguístico não se separa do cognoscente. Antecipando-se ao conhecimento e à compreensão, a linguagem não se reduz, como vimos, a uma coleção de etiquetas das 
quais a criança extrairia noções e coisas que ela já consegue conceber. Vygotsky, por sua vez, afirma que o associacionismo não investiga as transformações dos modos de generalização e materialização do significado. Nesta afirmação há a demarcação de uma lacuna: a perspectiva associacionista reduziria a linguagem à sua face instrumental, pois não permitiria explicar as transformações estruturais e psicológicas postas em marcha com o advento da linguagem. Segundo o autor, o significado da palavra altera a relação entre pensamento e palavra, sendo o próprio significado o elemento que lhe permite ultrapassar uma abordagem meramente instrumental da linguagem e considerá-la como fundamento da estruturação e organização do pensamento. A linguagem não se reduz a um simples reflexo da atividade do pensamento e este, por sua vez, não é concebido antes da linguagem. $\mathrm{O}$ pensamento, segundo essas linhas de compreensão, seria continuamente reestruturado pela linguagem, daí a correção feita pelo autor de que a linguagem não expressa o pensamento, que, antes, realiza-se na palavra.

Piaget vincula a linguagem aos modos mais primitivos de organização do real pela criança e observa que as diversas conexões causais e espaçotemporais se constroem sob a influência dos porquês e das questões de origem que a linguagem permite multiplicar. Por outro lado, quando o autor pesquisa o pensamento simbólico, trabalha o tempo inteiro com o material linguístico que recolhe das crianças, estabelecendo reciprocidades entre linguagem e pensamento e indicando relações entre a manifestação verbal e sua interferência no plano da construção do símbolo. O pensamento simbólico, nesta abordagem, relaciona-se com preocupações vitais da criança e a linguagem exerce um papel central nas explicações produzidas pela criança. A palavra corrobora e mesmo constitui a ultrapassagem de um encontro perceptivo com o objeto em direção à construção de constelações simbólicas que definem o funcionamento específico do ser humano. Mais uma vez, encontramos uma concepção do funcionamento da linguagem que pressupõe o abandono da noção de uma atividade perceptiva sem a mediação da linguagem e o avanço em direção à noção de um processo mental que compõe imagens e constelações simbólicas. Nesse trabalho de composição, que ultrapassa o encontro direto entre sujeito e objeto, a linguagem surge como fundamento organizador da realidade. Sem dúvida, existem muitas diferenças e divergências entre as concepções de linguagem dos três autores em questão, mas, certamente, esses autores fizeram parte de uma geração de teóricos que recolocaram o sujeito no centro das questões epistemológicas e, assim, recolocaram o sujeito no centro das pesquisas no campo da linguagem. Este "ato" teórico e - por que não dizê-lo? - político nos permite hoje buscar, sob as teorizações em torno da linguagem na criança, importantes formulações sobre a constituição da criança como sujeito.

\section{REFERÊNCIAS}

Lemos, C. T. G. (2002 Outubro). Sobre fragmentos e holófrases. In Colóquio LEPSI IP/FE-USP: Os adultos, seus saberes e a infância, São Paulo, SP, Brasil, 4.

Piaget, J. (n.d.). A representação do mundo na criança. São Paulo: Record.

Piaget, J. (1975). A formação do símbolo na criança: imitação, jogo, sonho e representação. Rio de Janeiro: Zahar

Vygotsky, L. S. (1989). Pensamento e linguagem (2a ed). São Paulo: Martins Fontes.

Vygotsky, L. S. (1999). Psicologia da arte. São Paulo: Martins Fontes.

Vygotsky, L. S. (2001). A construção do pensamento e da linguagem. São Paulo: Martins Fontes.

Wallon, H. (1984). L'enfant turbulent: recueil d'observations. Paris: PUF.

Wallon, H. (1989). As origens do pensamento na criança. São Paulo: Manole.

Wallon, H. (1995). A evolução psicológica da criança. Lisboa: Edições 70.
Endereço para correspondência:

Caciana Linhares Pereira. Rua Silva Paulet, 1854, ap. 801, Bloco B, Bairro: Aldeota, CEP 60120-021, Fortaleza-CE, Brasil. E-mail: cacianalinhares@gmail.com. 